\title{
RANCANG BANGUN SISTEM APLIKASI PEMESANAN KAMAR PADA HOTEL MAHARANI
}

\author{
Salman Alfarisi \\ Universitas Indraprasta PGRI \\ Jalan Nangka No.58 C, Tanjung Barat, Jakarta \\ salman.hotaru@gmail.com
}

\begin{abstract}
ABSTRAK
Belakangan ini sudah cukup banyak penyewaan kamar yang kita jumpai sering kali terlihat tidak teratur. Ini disebabkan oleh pendataan yang dilakukan belum terkomputerisasi yang artinya pencatatan kegiatan masih disimpan dalam beberapa berkas, yang mungkin akan menyebabkan ada kekurangan-kekurangan atau kesalahan-kesalahan yang sering dilakukan oleh karyawan bagian penyewaan kamar seperti kurangnya informasi mengenai kamar yang disewa apakah sudah selesai disewa atau belum, dan untuk mencari type kamar yang diinginkan diperlukan waktu yang relatif lama. Tujuan perancangan sistem pemesanan kamar ini adalah untuk mempermudah dalam mengelola data pemesanan kamar yang terdapat di Hotel Maharani agar pekerjaan menjadi efektif dan efesien. Selain itu sistem ini dapat membantu menyelesaikan permasalahan pemesanan kamar Hotel Maharani dapat terselesaikan dengan cepat, tepat, akurat guna mengefesiensikan waktu pekerjaan. Metode penelitian yang dipakai dalam penelitian ini adalah metode grounded research. Setelah dilakukan pengujian, Sistem pemesanan kamar ini dapat memenuhi kebutuhan akan suatu proses pemesanan kamar yang tepat guna dan cepat serta efektif dan efisien. Rancang bangun sistem pemesanan kamar ini menggunakan bahasa Java dengan IDE (Integrated Development Environment) dan untuk basis data menggunakan software mysql.
\end{abstract}

Kata Kunci: sistem, pemesanan, hotel

\begin{abstract}
Lately, there have been quite a number of room rentals that we encounter often look disorganized. This is because the data collection has not been computerized, which means that the recording of activities is still stored in several files, which may cause deficiencies or mistakes that are often made by room rental employees, such as lack of information about the rooms being rented, whether they have been rented or not. not yet, and to find the type of room you want takes a relatively long time. The purpose of designing this room reservation system is to make it easier to manage room reservation data at Maharani Hotel so that work becomes effective and efficient. In addition, this system can help solve the problem of booking a Maharani Hotel room, which can be resolved quickly, precisely, accurately in order to make work time efficient. The research method used in this research is grounded research method. After testing, this room reservation system can meet the need for an appropriate and fast and effective and efficient room reservation process. The design of this room reservation system uses the Java language with an IDE (Integrated Development Environment) and for the database uses the mysql software.
\end{abstract}

Key Word: System, Reservation, Hotel

\section{PENDAHULUAN}

Kemajuan teknologi yang sangat cepat sampai saat sekarang, dalam dunia ilmu komputer dan aplikasi desktop sudah sangat membantu dalam proses bisnis di dunia usaha. Pada era dahulu, semua pekerjaan atau kegiatan dilakukan secara manual sehingga seringkali kita dibatasi oleh ruang, waktu dan jarak. Kemajuan ilmu pengetahuan saat ini ditandai dengan banyaknya perkembangan teknologi sehingga banyak dihasilkan alat-alat canggih dan mutakhir. Perkembangan teknologi yang semakin maju dan modern khususnya pada bidang teknologi dan ilmu informatika, membuat beberapa perusahaan berusaha mengembangkan sayapnya agar selalu unggul dari perusahaan lain.

Hotel Maharani saat ini masih menggunakan pengolahan data yang bersifat pencatatan dalam sistem lama. Seluruh bukti transaksi pada tiap harinya dikelola dan dilakukan pencatatan dan pengarsipan ke dalam sistem lama untuk selanjutnya dilakukan pengolahan data setiap transaksi. Tiap kamar yang selesai disewa dicatat dalam buku penyewaan kamar yang bertujuan mempermudah karyawan atau admin melakukan searching atau cari data 
penyewaan kamar ketika ada pelanggan hotel yang ingin booking atau check-in. Dengan semakin banyaknya jumlah transaksi dalam alur bisnis penyewaan kamar hotel yang terjadi di tiap harinya, cara tersebut ternyata menyulitkan karyawan atau admin dalam proses pencarian data yang membuat proses dalam mendapatkan informasi yang diinginkan menjadi terlambat. Disamping itu, hal ini menyebabkan menjadi lambat dalam pembuatan laporan kegiatan di hotel karena karyawan atau admin dalam pembuatan report atau laporan harus mencari data-data yang telah diarsipkan sebelumnya Maka dari itu diperlukan suatu sistem agar dapat membantu proses penyewaan kamar pada hotel maharani secara efektif dan efesien.

Menurut (Sutabri,2012) di dalam teorinya menyebutkan bahwa Sistem adalah mempunyai karakteristik atau sifat-sifat tertentu yang mencirikan bahwa hal tersebut bisa dikatakan sebagai suatu sistem, sistem merupakan suatu jaringan kerja yang saling berhubungan berkumpul bersama- sama untuk melakukan suatu kegiatan atau menyelesaikan suatu sasaran tertentu, dimana dari sistem tersebut akan siap untuk merancang bangun implementasi dan penggambaran, perencanan dan pembuatan sketsa atau pengaturan dari beberapa elemen yang terpisah ke dalam satu kesatuan yang utuh".

Menurut (Sugiar, 2014) dalam bukunya menyebutkan bahwa Aplikasi adalah program yang dibuat untuk melaksanakan tugas tertentu yang digunakan oleh pengguna computer. Menurut (Yuhefizar, 2012) Aplikasi merupakan program yang dikembangkan untuk memenuhi kebutuhan pengguna dalam menjalankan pekerjaan tertentu. Sedangkan menurut (AA Abdullah, 2017) aplikasi merupakan penerapan, penyimpanan sesuatu hal, data, permasalahan, pekerjaan ke dalam suatu saran atau media yang dapat digunakan untuk diterapkan menjadi sebuah bentuk yang baru. Berdasarkan pengertian para ahli dapat diambil suatu simpulan bahwa aplikasi adalah suatu program yang digunakan untuk mempermudah suatu pekerjaan.

Tujuan utama penelitian yang peneliti lakukan adalah membangun sistem pengolahan data penyewaan kamar yang dapat membantu proses penyewaan kamar, pencarian dan penetapan harga, membantu proses penyewaan kamar, pencarian dan penetapan harga, mempermudah adminitrasi dalam pembuatan laporan pemesanan kamar hotel.

Tersedianya sistem pengolahan data penyewaan kamar yang dapat memberikan kemudahan dalam proses penyewaan kamar di hotel maharani dan memberikan kemudahan dalam melakukan proses/transaksi penyewaan kamar.

\section{METODE PENELITIAN}

Metode penelitian dalam membangun sistem aplikasi ini adalah metode grounded research yakni penekanan analisis pada tindakan dan situasi yang problematik sehingga atau disebut juga sebaga imetode pemecahan masalah (Titscher, 2011) suatu metode penelitian berdasarkan pada fakta dan menggunakan analisis perbandingan dengan tujuan mengadakan generalisasi empiris, menetapkan konsep, membuktikan teori, mengembangkan teori, pengumpulan dan analisis data dalam waktu yang bersamaan.

Dalam pengumpulan data, peneliti melakukan beberapa metode untuk mendapatan data primer dan sekunder.

\section{Wawancara}

Wawancara ialah proses komunikasi atau interaksi untuk mengumpulkan informasi dengan cara Tanya jawab antara peneliti dengan informan atau subjek penelitian (Hamzah, 2019a). Peneliti melakukan penelitian dengan mengadakan tatap muka langsung dengan pertanyaan kepada pihak yang bertanggung jawab mengenai bagaimana proses penyewaan kamar hotel pada Hotel Maharani, aliran data, proses penyewaan kamar hotel, laporan penyewaan kamar hotel, dan juga sistem yang berjalan saat ini dan apa saja yang dibutuhkan dalam proses penyewaan kamar hotel tersebut. Metode wawancara ini penulis tunjukkan kepada orang-orang yang berkecimpung dalam proses pengelolaan Hotel Maharani.

\section{Pengamatan Langsung (Observasi)}

Observasi adalah teknik pengambilan data dengan cara mengamati secara langsung suatu keadaan atau situasi dari sebuah subjek penelitian (Hamzah, 2019b). Peneliti mempelajari dan mengamati sistem komputerisasi yang terdapat Hotel Maharani 
serta keterkaitan antara subsistem dengan yang lain dengan meninjau tentang penyewaan kamar hotel yang ada pada perusahaan tersebut, kemudian mengadakan pengamatan untuk mengetahui sistem yang sudah ada yakni pada proses penyewaan kamar hotel guna mendapatkan kesimpulankesimpulan dari masalah dengan tujuan merancang sebuah sistem yang baru. Data yang didapatkan oleh peneliti dengan pengamatan langsung dari sistem yang sedang ada, dengan pencatatan, dan pengumpulan data-data yang dilakukan pada Hotel Maharani.

\section{Kepustakaan}

Peneliti melakukan pengumpulan data dengan cara mempelajari beberapa buku, jurnal, sarana perpustakaan, dan catatan-catatan kuliah yang berhubungan dengan yang penelitian ini.

\section{Langkah-langkah Pengembangan Sistem}

Dalam penelitian ini, peneliti menggunakan metode waterfall. Dibawah ini ialah tahapan metode waterfall, yaitu (Udaksana \& Kusaeri, 2018):

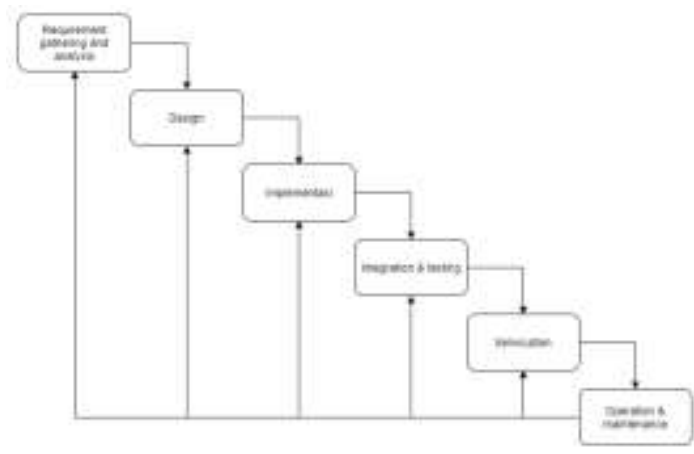

Gambar 1. Metode Waterfall

\section{Requirement gathering and analysis}

Kebutuhan dikumpulkan secara menyeluruh untuk dilakukan analisis dan memberikan definisi tentang kebutuhan yang harus dicapai oleh sistem. Informasi ini peneliti dapatkan dari proses wawancara, diskusi, atau survey.

\section{Design}

Desain adalah merancang gambaran software sebagai acuan untuk pengkodean. Biasanya desain ini dibuat dengan penggunaan Flowchart, DAD, UML atau Entity Relationship Diagram (ERD).

\section{Implementasi}

Adalah fase pengkodean berdasarkan dari desain yang telah dilakukan. Proses ini menghasilkan beberapa modul yang nantinya digabung atau di satukan pada fase berikutnya.

\section{Integration \& testing}

Fase ini adalah penyatuan atau penggabungan modul yang telah dirancang pada fase implementasi setelah itu dilakukan testing atau pengujian agar bisa memastikan bahwa sistem yang dibuat telah sesuai dengan desain atau rancangan dan fungsinya.

\section{Verification}

Pada fase verifikasi, user akan melakukan pengujian pada perangkat lunak yang sudah dibuat, apakah perangkat lunak sudah sesuai atau belum sesuai.

\section{Operation \& maintenance}

Pada fase ini akan dilakukan pengoperasian perangkat lunak yang telah rampung dibuat, setelah itu dilakukan pemeliharaan berkala jika ada kesalahan atau kekurangan dalam sistem.

\section{HASIL DAN PEMBAHASAN}

Use case diagram terdiri dari sebuah aktor dan interaksi yang dilakukannya (Kurniawan, T. Bayu, 2020). Use case dari sistem aplikasi pemesanan kamar hotel maharani ini adalah staf admin sebagai aktor yang mempunyai hak menginput data kamar, input data housekeeping, input data tamu, input data status kamar dan input laporan untuk manajer hotel.

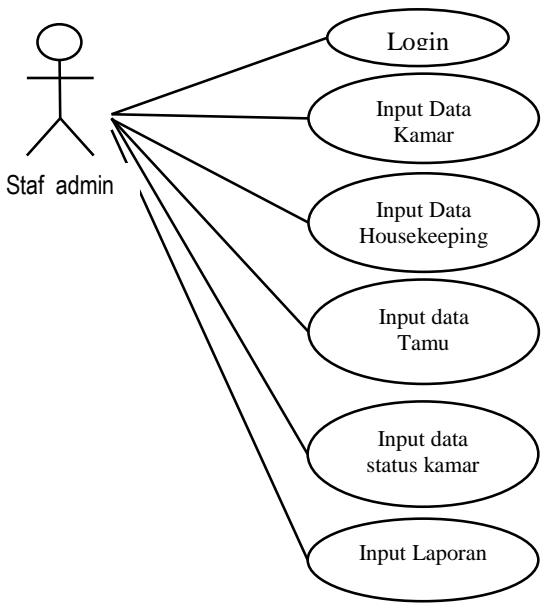

Gambar 2. Use Case Sistem Aplikasi Pemesanan

\section{Entity Relationship Diagram (ERD)}

ERD (Entity Relationship Diagram) merupakan pemodelan basis data yang berelasi dan juga merupakan diagram yang menunjukan informasi suatu basis data (Tabrani, Suhardi, \& Priyandaru, 2021). 


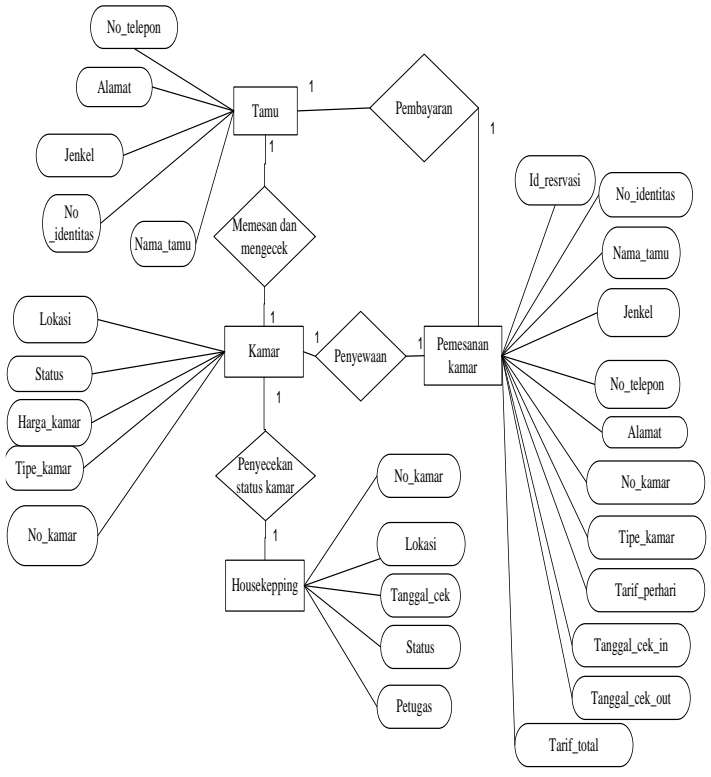

Gambar 3. Entity Relationship Diagram Sistem Aplikasi Pemesanan kamar Hotel Maharani

\section{Tampilan Login}

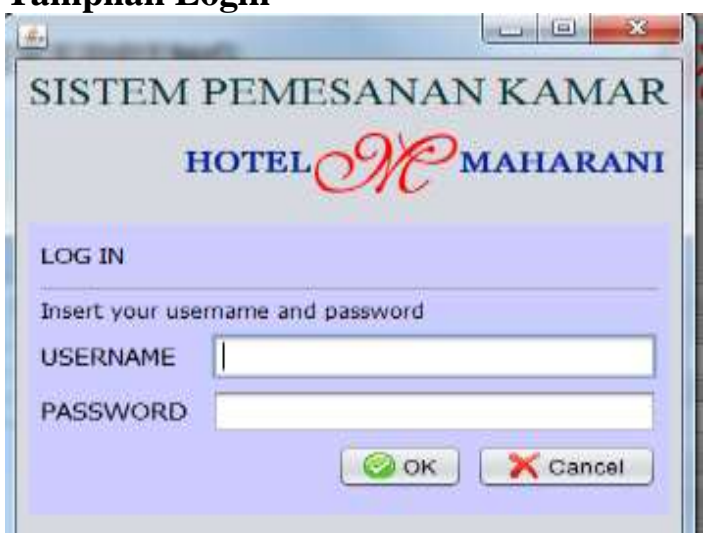

Gambar 4. Tampilan Halaman Login

Tampilan layar ini terletak pada pertama kali aplikasi dijalankan. Tampilan login akan menampilkan dua textfield yakni username dan password yang harus di isi oleh admin atau user ketika ingin mengakses kedalam halaman atau menu utama. Username dan password yang di isikan harus sesuai dengan yang telah di simpan dalam basis data. Ketika username dan password nya telah sesuai, maka admin atau user akan masuk ke halaman menu utama sistem aplikasi.

\section{Tampilan Menu Tamu}

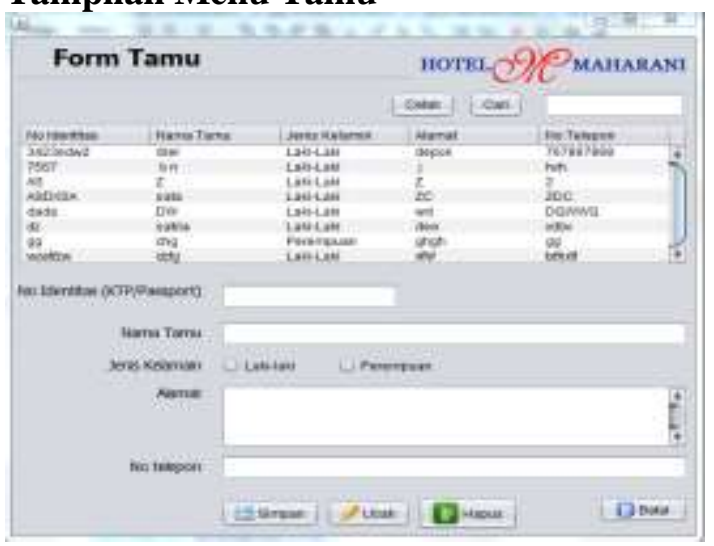

Gambar 5. Tampilan Menu Tamu

Layar di atas menampilkan tampilan form tamu. Pada layar form tamu untuk menginput data tamu yang terdiri dari no identitas, nama tamu, jenis kelamin, alamat, dan no telepon.

\section{Tampilan Form Kamar}

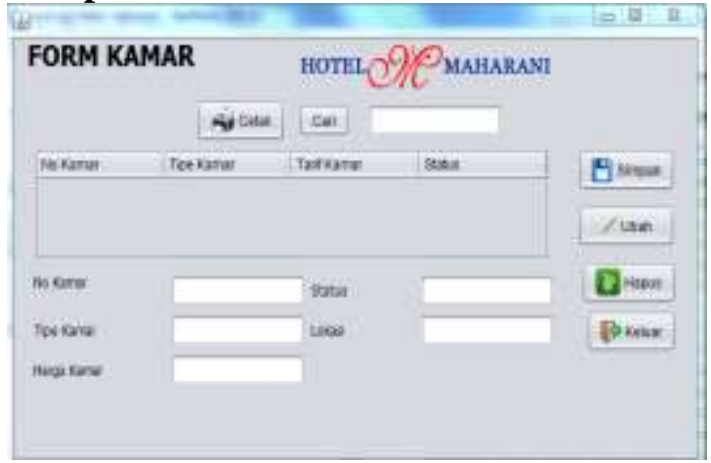

Gambar 6. Tampilan form kamar

Layar di atas menampilkan tampilan form kamar. Pada layar form kamar untuk menginput data kamar yang terdiri dari no kamar, tipe kamar, harga kamar, status, dan lokasi.

Tampilan form pemesanan kamar

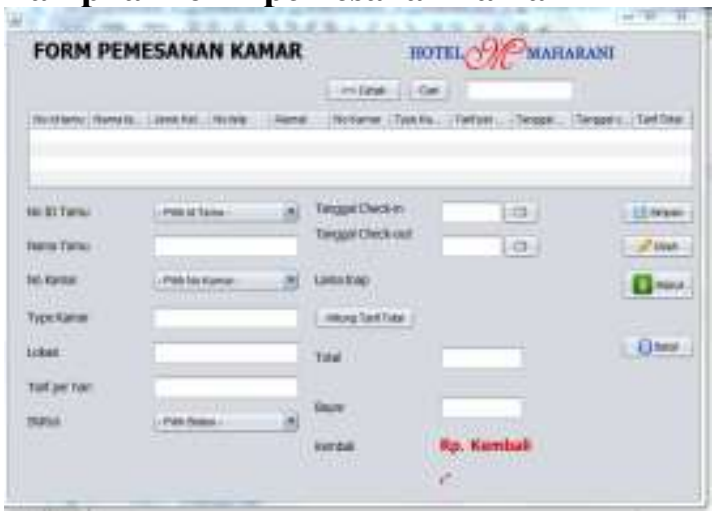

Gambar 7. Tampilan form pemesanan kamar 
Layar di atas menampilkan tampilan form reservasi. Pada layar form reservasi untuk menginput data penyewaan yang terdiri dari no id tamu, nama tamu, no kamar, tipe kamar, lokasi, tarif perhari, status, tanggal cek in, tanggal cek out, lama inap, hitung atrif total, total, bayar, dan kembali

\section{Tampilan form housekeeping}

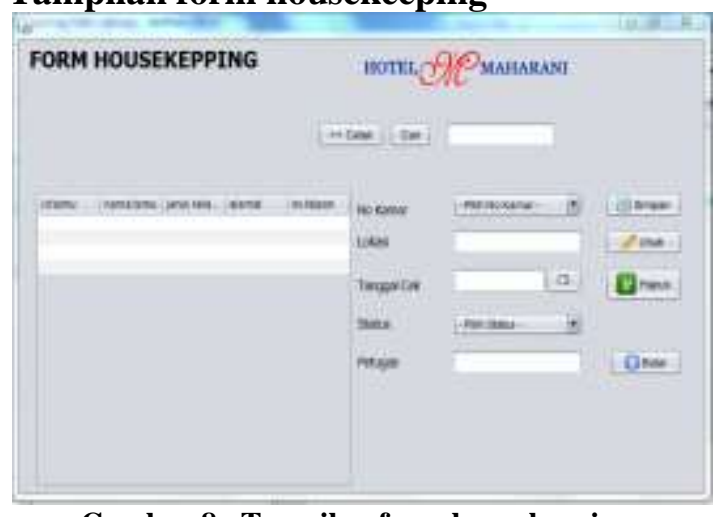

Gambar 8 . Tampilan form housekeeping

Layar di atas menampilkan tampilan form housekepping. Pada layar form housekepping untuk mengganti status kamar siap jual yang terdiri dari no kamar, lokasi, tanggal cek, status, dan petugas.

\section{SIMPULAN DAN SARAN}

Dengan adanya Sistem Aplikasi Pemesanan Kamar pada Hotel Maharani semua kegiatan yang berhubungan dengan pengolahan data Penyewaan Kamar dapat berjalan dengan baik dan lancar. Pada aplikasi ini, bagian Keuangan dapat menangani pekerjaan penginputan data-data Penyewaan Kamar dengan cepat dan akurat serta dapat di update dengan mudah. Dan dengan adanya aplikasi ini diharapkan akan mempermudah kegiatan atau aktivasi pekerjaan yang memerlukan kecepatan dan ketetapan informasi.

Kecepatan dan ketepatan hasil perancangan ini juga membutuhkan partisipasi aktif dari pemakai sistem, terutama kedisiplinan para pelaksana yang menangani secara langsung pada sistem yang dirancang.

Beberapa simpulan yang dapat peneliti sampaikan adalah sebagai berikut :

1. Sistem aplikasi pemesanan kamar pada Hotel Maharani lebih mempermudah pekerjaan dan dapat meningkatkan kelancaran proses penyewaan kamar

2. Pihak admin hotel dapat mempercepat pengolahan data dan pembuatan laporan serta informasi yang dihasilkan lebih akurat dan tepat waktu.

3. Sistem aplikasi pemesanan kamar ini dapat membantu menhasilkan keperluankeperluan yang akurat, cepat dan relevan, sehingga pelayanan terhadap seluruh mitra kerja dengan bagian lain meningkat dan semakin membaik

Adanya Sistem Aplikasi Pemesanan Kamar pada Hotel Maharani ini diharapkan mampu memberikan manfaat bagi pihak hotel. Untuk mendapatkan manfaat yang maksimal, maka peneliti mengajukan beberapa saran untuk pengetahuan Sistem aplikasi Pemesanan Kamar pada Hotel Maharani:

1. Sistem Aplikasi Pemesanan Kamar pada Hotel Maharani perlu mendapatkan penambahan data yang lebih lengkap.

2. Penambahan fitur keamanan seperti enkripsi data, sangat dianjurkan agar data lebih aman.

3. Sistem ini diharapkan dapat berkembang dan dimanfaatkan sebagaimana mestinya tanpa adanya penyalahgunaan pada informasi yang diberikan.

\section{DAFTAR PUSTAKA}

AA Abdullah, S. S. (2017). Meningkatkan Kemampuan Berpikir Kritis Melalui Pembelajaran Statistika Berbasis Pendidikan Politik Di Lingkungan Sekolah. Jurnal Gantang, 2, 1-9.

Hamzah, A. (2019a). Metode Penelitian Kualitatif (1st ed.). Malang: Literasi Nusantara.

Hamzah, A. (2019b). Penelitian Berbasis Proyek (1st ed.). Malang: Literasi Nusantara.

Kurniawan, T. Bayu, S. (2020). Perancangan Sistem Aplikasi Pemesanan Makanan dan Minuman Pada Cafetaria NO Caffe di TAnjung Balai Karimun Menggunakan Bahasa Pemrograman PHP dan My.SQL. Journal of Chemical Information and Modeling, 53(9), 16891699.

Sugiar, Y. (2014). KOMPUTER Si Mesin Pintar.

Sutabri, T. (2012). Analisa Sistem Informasi. Yogyakarta: Graha Ilmu.

Tabrani, M., Suhardi, \& Priyandaru, H. (2021). Sistem Informasi Manajemen Berbasis Website Pada Unl Studio Dengan Menggunakan Framework 
Codeigniter. Jurnal Ilmiah M-Progress, 11(1), 13-21.

Titscher. (2011). Metode Analisis Teks dan Wacana. Yogyakarta: Pustaka Pelajar.

Udaksana, A. P. C., \& Kusaeri, W. R. (2018).

Rancang Bangun Aplikasi Digital School Dengan Java NetBeans IDE 8.1. Irons, 332-336.

Yuhefizar. (2012). Cara Mudah Membangun Website Interaktif Menggunakan CMS Joomla. PT. Elex Media Komputindo. 